\title{
THE COORDINATION OF COMPLEX PRODUCT SYSTEMS PROJECTS: A CASE STUDY OF AN R\&amp;amp;D MULTI-PARTY ALLIANCE
}

Adalberto Franca

The self-archived postprint version of this journal article is available at Linköping University Institutional Repository (DiVA):

http://urn.kb.se/resolve?urn=urn:nbn:se:liu:diva-164458

N.B.: When citing this work, cite the original publication.

Franca, A., (2019), THE COORDINATION OF COMPLEX PRODUCT SYSTEMS PROJECTS: A CASE STUDY OF AN R\&amp;amp;D MULTI-PARTY ALLIANCE, International Journal of Innovation Management, 23(3), UNSP 1950024. https://doi.org/10.1142/S1363919619500245

Original publication available at:

https://doi.org/10.1142/S1363919619500245

Copyright: World Scientific Publishing

http://www.worldscientific.com/ 


\title{
THE COORDINATION OF COMPLEX PRODUCT SYSTEMS PROJECTS: A CASE STUDY OF AN R\&D MULTI-PARTY ALLIANCE
}

\author{
JOSÉ ADALBERTO FRANÇA JUNIOR
}

\author{
Department of Engineering and Management \\ Linköping University, Linköping, SE-58183, Sweden \\ betoordie@gmail.com
}

\begin{abstract}
In this paper, we address the evolution of coordination between multiple and diverse partners in a complex $R \& D$ innovation project. Because common understanding is crucial to help coordination in complex and uncertain contexts, we performed an in-depth case study of a large European project aiming to investigate the interaction between common understanding and coordination mechanisms during the life cycle of a CoPS multi-party project. We found that coordination mechanisms are combined according to different stages of the project and create common understanding by managing tasks and roles as the project unfolds. Moreover, to cope with high interdependent tasks and many diverse partners, it seems crucial to implement an iterative process where tasks and roles evolve and mature progressively, and problems are identified earlier, leading to a validated and consistent result.
\end{abstract}

Keywords: Coordination; Coordination Mechanisms; Common Understanding; CoPS; Multi-party Alliances

\section{Introduction}

The literature of Complex Product Systems (CoPS) emphasizes the importance of coordination between focal firms, partner suppliers, regulators, users and specialist small firms, in R\&D innovation projects (Davies et al., 2011). Common understanding in CoPS is understood as essential for coordination in Research and Development (R\&D) projects and plays a fundamental role to cope with differing organization cultures, difficulties in contractual relations, and the need to integrate different domains of knowledge (Davies et al., 2011).

The importance of common understanding in coordinating multi-party projects is also widely accepted in the literature of multi-party alliances (García-Canal, Valdés \& Ariño, 2003; Luo \& Park, 2004). However, scant attention has been paid to the dynamics of coordination and common understanding in CoPs innovation projects. Because these types of projects are becoming increasingly common, the purpose of this study is to investigate the evolution of coordination by examining the interaction between common understanding and coordination mechanisms during the life cycle of a CoPS multi-party project. More specifically, this research aims to answer this question: How does common understanding interact with coordination mechanisms, and how do they evolve together helping and facilitating coordination in CoPS multiparty projects?

In order to address the research question, it was conducted an in-depth case study of a multi-party R\&D project, the MIDCAS (Mid Air Collision Avoidance System). This project consists of a large industrial consortium of 13 European 
companies from five different countries in the aerospace industry. The focus of MIDCAS is to develop leading-edge technologies needed for Unmanned Aerial Systems.

The findings point the answer at managing tasks and roles as the project unfolds, by: adapting different combinations of coordination mechanisms according to different stages of the project; and implementing an iterative process where tasks and roles evolve and mature progressively, and problems are identified earlier, leading to a validated and consistent result.

It was also found that common understanding is built by continually: refining tasks and tasks solutions through continuous improvement of impersonal coordination of the codified knowledge base; converging the different perspectives of roles and tasks by adapting personal and virtual coordination mechanisms as the project unfolds; and using virtual coordination as a baseline to complement and reinforce the other mechanisms.

\section{Managing CoPS Developments}

Complex systems are usually developed in multi-party projects and often customized for specific customers, making the development difficult to execute and posing challenges to the innovation process (Hobday, 1998). CoPS projects are uncertain activities and "project managers and engineers must recognize that unexpected events and unknown risks will arise and use their tacit knowledge, judgment and experience to cope with them" (Davies et al., 2011). Moreover, project collaboration in CoPS takes place across a project network of partner suppliers (Eslami \& Lakemond, 2015), users (Baraldi, 2009), customers and competitors (Liu \& Su, 2014), regulators, and specialist small firms (Davies et al., 2011). It is important therefore, that all stakeholders maintain a common understanding of the project (Simpson et al., 2013).

In a study to identify the main problems, or "hot spots" that firms experience in the development and production of CoPS, Hansen \& Rush, (1998) grouped these hot spots into three overlapping categories: requirements identification, process issues and coordination of information. Related to coordination and information, they specifically identify issues such as the integration of knowledge to accomplish the tasks, information and learning needed to manage new technologies, and interactions with customers (Hansen \& Rush, 1998). Typically, problems arise when the roles of team members and the information about who is responsible for what are unclear and not well defined in the beginning. It follows that time and extra costs are spent discussing these responsibilities (Hansen \& Rush, 1998). Such problems are closely linked with the level of common understanding of the group related with the roles of participants and tasks of the project.

\section{Coordination}

Coordination research has focused on many different contexts and perspectives, such as interdependence (Faraj \& Xiao, 2006; Malone, 1994; Thompson, 1967), interaction (Heath, Hindmarsh \& Luff, 1999), cooperation (Pinto, Pinto \& Prescott, 1993), capabilities (Barqawi et al., 2015), communication (Ballard, 2003), knowledgesharing (Bechky, 2003; Carlile, 2002), and uncertainty (Faraj \&Xiao, 2006). Because CoPS projects have a high degree of interdependence between the tasks to be performed, and a high uncertainty related (Davies \& Mackenzie, 2014), In this paper, 
it is adopted the definition of Faraj \&Xiao, (2006) of coordination as "the integration of organizational work under conditions of task interdependence and uncertainty" (Faraj \&Xiao, 2006: P1156). Integrating a collective set of interdependent tasks is facilitated by coordinating mechanisms (Faraj \& Xiao, 2006; Okhuysen \& Bechky, 2009), which are often distinguished by plans, rules, goals, objects, schedules, routines and face-to-face meetings (Van De Ven, Delbecq \& Koenig, 1976). In the context of complex collaborative settings, such as in CoPS R\&D projects, knowledge is usually integrated through a combination of impersonal and personal coordination mechanisms. These projects rely on statements of work, evolving product and process specifications, planning, and both scheduled and unplanned face-to-face meetings (Enberg, 2012).

Classical theories of organization have described coordination in relation to work division, horizontal and vertical linkages in the organization structure and the need for information processing between units and people (Mintzberg, 1973). They distinguish between personal and impersonal modes of coordination. Personal coordination relies on coordination by feedback between individuals, which allows for mutual task adjustments. While impersonal coordination builds on programming such as the use of plans, schedules, rules, policies and procedures. In relation to the information-processing needs, Van de Ven, Delbecq \& Koenig (1976) argue that when tasks are highly interdependent and uncertain, they become more difficult for organizations to coordinate by impersonal means. Personal modes of coordination based on feedback are more effective means of information exchange, especially in the presence of tacit knowledge (Nonaka, 1994).

However, although coordination through feedback allows joint learning and may help in solving complex problems, it is also an expensive form of coordination as it requires more resources and efforts by the individuals involved (Prencipe \& Tell, 2001). Thus, when knowledge is highly explicit and can be easily codified, more impersonal forms of coordination may be beneficial. Therefore, firms need to make careful choices on how to coordinate work to maximize the benefits of knowledge integration (Grant, 1996).

In a multiple case study of five R\&D alliances, Faems, Janssens \& Van Looy, (2010), show that impersonal and personal mechanisms are combined differently according to different stages of the alliance process (i.e., negotiation vs operation stages), and for different purposes. Impersonal mechanisms were prevalent at initial stages to defer costly investments until necessary. Personal mechanisms dominated at the design stage, when problems first became apparent and were adopted to enhance joint problem-solving.

Moreover, in CoPS R\&D collaborations, innovation activities are often characterized by project organizations that are connected across multiple sites. These projects represent an environment characterized by "working together apart" relying on information and communication technology, such as video-conferences, common IT platforms, e-mails, or simulation technologies (Zakaria, Amelinckx \& Wilemon, 2004). These means of communicating and coordinating, can, in a geographically dispersed or virtual setting, put individuals in contact with each other, facilitate team-work, enable exposure and therefore accelerate knowledge creation (Alavi \& Leidner, 2001).

However, virtual communication also poses specific challenges related to creating trust, creativity and management (Chamakiotis et al., 2014; Greenberg et al., 2007). It is more difficult to develop high-quality relationships and informal spontaneous work conversations (Furst et al., 2004). Reliance on electronic communications also increases the risk for faulty interpretations and erroneous stereotypes. Massey, Montoya-Weiss \& Hung, (2003) show that coordination in virtual 
projects is temporally patterned in complex ways. Early phases can be characterized by unbridled optimism, an over-reliance on electronic media and a relatively low degree of communication efforts based on feedback (Furst et al., 2004). This can be typically followed by a reality shock, increased levels of coordination through temporary faceto-face interactions, new agreements on how to operate forward and an evolving insight into the limits of virtual interactions.

\section{Common Understanding}

Common understanding is important when two or more actors carry out interdependent work and is often a result of agreed goals, contributions and benefits (Gulati, Wohlgezogen \& Zhelyazkov, 2012). In these situations, the actors need to share knowledge of the goals and objectives of the work, the activities that need to be performed, and the way the work is performed (Okhuysen \& Bechky, 2009). Common understanding refers to creating a shared conception about the work that is to be performed. It can be understood in three dimensions, i.e. related to (1) understanding of the task, (2) understanding of the knowledge of the different parties, and (3) an understanding of the broader context. All of these dimensions help providing a shared perspective of the task, and how each of the actors' role fits within the whole.

Common understanding can be created through different coordination mechanisms (Pinto, Pinto \& Prescott, 1993), and it is an important mean to accomplish coordination (Okhuysen \& Bechky, 2009). For instance, plans and rules help to create a common understanding of particular ways to complete tasks (Axelson \& Richtnér, 2014; Cannon-Bowers \& Salas, 2001; Okhuysen \& Bechky, 2009; Reagans, Argote \& Brooks, 2005), while objects (e.g. demonstrators and prototype machines) help groups translate their different understandings to create a common perspective of the tasks (Bechky, 2003).

Steen, Buijs \& Williams, (2013), emphasize the development of objects in an innovation project, like demonstrators and scenarios, as crucial to promote common understanding. In a context of complex projects, Steen, Buijs \& Williams, (2013) also highlight the importance of developing demonstrators in an iterative process to facilitate exploration, trying-out and learning. An iterative process is a methodology of engineering design where managers divide the complete design process into discrete design decisions (von Hippel, 1990). An iteration is the repetition of design tasks due to the arrival or discovery of new information (Smith \& Eppinger, 1997).

It must be noted that, in multi-party alliances, common understanding can be undermined as there are more interests and greater diversity to be harmonized than in dyadic alliances (García-Canal, Valdés \& Ariño, 2003). Therefore, multi-party alliances induce additional complexity and coordination costs compared to dyadic relationships (García-Canal, 1996; Parkhe, 1993).

A synthesis of the previous findings points at a complex relationship between common understanding and coordination. This relationship is that in a context of uncertainty and interdependence, tasks and roles are complex to coordinate in a multiparty project. This complexity also makes difficult to create common understanding about the tasks to be performed and about who has the role to execute the tasks.

In this paper, coordination is distinguished between impersonal coordination, virtual coordination (interaction through electronic media), and personal coordination (face-to-face interaction). These are operationalized further in the next section. It is expected that the choice for a certain combination of coordination mechanisms is 
affected and affects the creation of common understanding between partners about tasks and roles. The next section presents the data and methods used.

\section{Methodology}

\section{Research Design}

To address the research question, it was performed an in-depth case study of a multi-party R\&D project between firms operating in the aerospace industry. The project is the Mid-air Collision Avoidance System (MIDCAS), a consortium of 13 European industrial companies with the aim to develop unmanned aerial technologies. The project had a total budget of $€ 50$ million euros and $\mathrm{Saab} A B$, an aerospace company in Sweden, was assigned the overall coordination of the project

Case study research can be considered an investigation and analysis of a single or collective case, intended to capture the complexity of the object of study (Stake, 1995). It has also been defined by the unit of analysis, the process of study, and the outcome or end product, all essentially the case (Merriam, 1997). As a study design, the selection of methods in case study research is informed by research and case intuition, making use of people or observations of interaction that occur in physical space (Denzin \& Lincoln, 2008). Further, multiple data collection and analysis methods are adopted to develop and understand the case, shaped by context and emergent data (Stake, 1995).

Because the aim was to explore coordination issues in complex collaborations, a large project in terms of budget, number of participants and complexity was chosen.

The selected case represents the complex setting of a CoPS project and serves as an illustration of a particular and unique phenomenon, but also represents what (Siggelkow, 2007) refers to as a 'talking pig'. The uniqueness of MIDCAS can be verified in the large amount of budget for a European consortium ( $€ 50$ million euros), the large number of diverse participants ( 13 companies from 5 countries and many other stakeholders), and the complex and interdependent nature of the R\&D tasks. All of these characteristics make the interaction between coordination and common understanding more observable, as its dynamic is more striking. The reason of this pronounced dynamic is that not all CoPS projects have so many diverse partners and so high interdependence between the tasks, as the MIDCAS project has.

Therefore, our case serves as an interesting scenario to analyse coordination issues. Our case can also be referred as an instrumental case, where the interest is to understanding something inside the case, that can be transferable to other contexts, and not the case itself (Stake, 1995). This scope of coordination issues inside the MIDCAS case, can supports reasonable analytical generalization, helping the external validity of the research (Riege, 2003).

The breadth of complexity of the MIDCAS project was the main reason for choosing an emergent research methodology (Suter, 2011), which relies on inductive reasoning and a continual interplay between data, literature and developing interpretation. This allowed to choose, during the research, the scope, among many, that was more prevalent inside the issues of coordination. Therefore, the research was designed as suggested by (Stake, 1995). He advocates a flexible design, with the researcher being concerned in the beginning, only with the issues and issue questions, which later, will lead to the design of the research questions.

\section{Data collection}


Data was collected through 12 interviews at five of the industrial partners involved in MIDCAS, two full days of study visits to Saab's facilities, frequent informal discussions with Saab's managers, and numerous internal reports of the project that served as secondary information.

The selection of the industrial partners was made based on their higher involvement in the project's coordination. The main coordinator of the whole project was Saab, the project leader. The other four selected partners for the interviews were coordinators of the partners inside their own countries and also were leading most of the working packages inside the project. Having key informants from multiple sources of diverse industrial coordinators and also secondary information about the project helped the construct validity of the research (Riege, 2003).

The interviews have been performed at Saab with the Chairman of the Steering Committee, the Project Manager, the Chief Engineer, the Saab Director of Future Business, and the Director of R\&T Strategy. Interviews have also been performed with National members of the Steering Committee, National Industry managers, National Industry Chief Engineers and Work Package leaders at six industrial partners (12 interviewees in total, five of which were from the coordinator, Saab). All interviews were semi-structured, conducted according to an interview guide and lasted about 1,5 to 2 hours. During the interviews, I made detailed notes, and also transcribed recordings.

In the first phase of the research, started during the spring of 2015 , it was performed a first round of five interviews with Saab's employees in Sweden. The interviewees were key managers working with the company's strategy. During two days of study visits in the company, it was possible to have informal discussions about MIDCAS, but also ongoing and previous projects as reference for comparison. As the MIDCAS project had a strong orientation towards standardization, a large quantity of documentation was released to inform stakeholders, including objectives, reports and press releases on the results of the project. I was given access to a detailed and extensive secondary documentation (ANNEX 1) that was produced to inform non-experts of the R\&D activities, which provided a detailed understanding of the project. During these process, a set of categories and themes were being created based on the analysis of the data.

After becoming acquainted with MIDCAS, I performed seven additional interviews in 2016 at four industrial partners in France, Germany and Italy. The interview's guide was slightly modified including new categories and themes emerged from the previous interviews and downplaying others.

\section{Analysis}

The process of data analyses was conducted simultaneously with data collection, compatible with an emergent design as suggested by (Stake, 1995). The coding was performed by separating ideas, so that categories and themes relevant to the research questions could be identified as proposed by (Noble \& Smith, 2014). This was a concurrent and interactive process of finding patterns inside the data during the entire research. This interaction was done by continuously revisiting the data, the literature and converging interpretations with key managers from the leading firm of the project, Saab. This interactive process increased the internal validity and reliability of the research (Riege, 2003). 
In the process of finding categories, new categories emerged, and others were downplayed. For instance, the category of coopetition (Bengtsson \& Kock, 2000) was initially thought as an important theme, which, only later, was downplayed for not be considered pertinent to the project. Based on the categories, the themes were also evolving. Table 1 shows the developing categories (the downplayed, the relevant that were kept from the beginning, and the emergent ones). It also shows the final themes related with the categories that were used to draw the final discussion in the paper.

\begin{tabular}{|c|c|c|}
\hline Downplayed categories & $\begin{array}{c}\text { Relevant and emerged } \\
\text { categories }\end{array}$ & Final themes \\
\hline $\begin{array}{l}\text { Coopetition } \\
\text { Unintended knowledge leakage } \\
\text { Trust } \\
\text { Standardization }\end{array}$ & $\begin{array}{l}\text { Consensus } \\
\text { Extended workshops } \\
\text { Stakeholders workshops }\end{array}$ & Common Understanding \\
\hline Suppliers Versus System Integrators & $\begin{array}{l}\text { Iterative approach } \\
\text { Demonstrators }\end{array}$ & Iterative process \\
\hline & $\begin{array}{l}\text { Multi-party } \\
\text { CoPS }\end{array}$ & Multi-party CoPS R\&D projects \\
\hline & $\begin{array}{l}\text { Task interdependence } \\
\text { Emergent tasks } \\
\text { Tasks assignment }\end{array}$ & Tasks and Roles \\
\hline 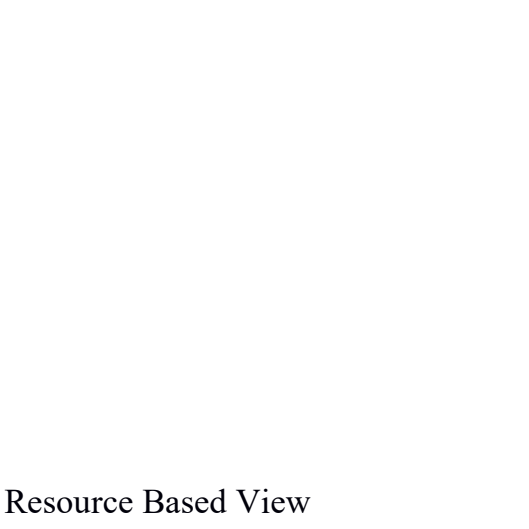 & $\begin{array}{l}\text { Face-to-face Meetings } \\
\text { Technical Specifications } \\
\text { Stakeholders' reports } \\
\text { Statement of Work } \\
\text { Skype meetings } \\
\text { Tele-conferences } \\
\text { E-mails } \\
\text { IT Software }\end{array}$ & Coordination mechanisms \\
\hline
\end{tabular}

Table 1: Developing categories and final themes coded from data.

\section{The MIDCAS Project}

\section{Background of the project}


In 2009, the European Defense Agency (EDA) and its member nations funded the Mid-air Collision Avoidance System (MIDCAS), which was a partnership of 13 industrial European companies with knowledge on technologies needed for Sense and Avoid (S\&A) solutions. The main objective of this project was to contribute to the Remotely Piloted Aircraft System (RPAS) integration in the European civilian airspace, by jointly developing an S\&A function and agreeing on a future standard.

The project was carried out under supervision and authority of the Ministries of Defense (MOD) from five participating nations: Sweden, Germany, France, Italy and Spain. The company Saab had the coordination role among 13 industrial partners from those countries. Throughout the project, external stakeholders and regulatory bodies such as EASA, EUROCONTROL, EUROCAE and JARUS were also involved in the coordination process.

The project was focused on three parallel tracks with high level of interaction and interdependency; (1) to make progress on standards for S\&A; (2) to design a generic S\&A function; and (3) to design a S\&A demonstrator to be tested in manned and unmanned flights. The project relied on multiple activities in two different scenarios, the R\&D scenario, such as systems engineering, functional design, demonstrator design, tests, evaluation, safety studies; and the standardization scenario with standardization support between R\&D teams and stakeholders (customers, users and regulation authorities). All of these activities were integrated in an iterative process development logic with frequent feedback, which were identified within three levels of coordination stages:

- Initial stage: Conceptual development

- Design stage: Simulation, implementation and testing in manned and unmanned demonstrator

- Concluding stage: Simulation, implementation and testing in unmanned demonstrator and finalization.

The main R\&D tasks during the project included:

- Functional design of the S\&A

- S\&A simulations based on the initial design

- Implementation and evaluation of manned flight campaigns

- Implementation and evaluation of unmanned flight campaigns

- Standardization workshops with external and internal stakeholders.

Each main task was designed to be implemented in several iterations (figure 1), which also include subtasks (for simplicity, subtasks are referred to as tasks from now on). The tasks to be performed were: requirements elaboration, design solutions, design implementation, testing, test reports and so on. Each task had the respective actor's roles assigned in the contract and Statement of Work (SoW). Not all tasks can be predicted before, and new tasks emerged during the project, requiring new task assignments and consequent adjustments of roles.

\begin{tabular}{|c|c|c|c|}
\hline Stages & $\begin{array}{c}\text { Initial stage } \\
\text { Conceptual } \\
\text { development }\end{array}$ & $\begin{array}{c}\text { Design stage } \\
\text { Simulation, implementation and testing in } \\
\text { manned and unmanned demonstrator }\end{array}$ & $\begin{array}{c}\text { Concluding stage } \\
\text { Simulation, } \\
\text { implementation and } \\
\text { testing in unmanned }\end{array}$ \\
\hline
\end{tabular}




\begin{tabular}{|c|c|c|c|c|c|c|}
\hline & & & & & \multicolumn{2}{|c|}{$\begin{array}{l}\text { demonstrator and } \\
\text { finalization }\end{array}$} \\
\hline $\begin{array}{c}\text { Functional } \\
\text { Design of the } \\
\text { S\&A } \\
\end{array}$ & $\begin{array}{l}1^{\text {st }} \\
\text { iteration }\end{array}$ & $\begin{array}{l}2^{\text {nd }} \\
\text { iteration }\end{array}$ & $\begin{array}{l}3^{\text {rd }} \\
\text { iteration }\end{array}$ & $\begin{array}{l}4^{\text {th }} \\
\text { iteration }\end{array}$ & $\begin{array}{c}5^{\text {th }} \\
\text { iteration }\end{array}$ & \\
\hline $\begin{array}{c}\text { S\&A } \\
\text { simulations }\end{array}$ & & $\begin{array}{l}1^{\text {st }} \\
\text { iteration }\end{array}$ & $\begin{array}{l}2^{\text {nd }} \\
\text { iteration }\end{array}$ & $\begin{array}{l}3^{\text {rd }} \\
\text { iteration }\end{array}$ & $\begin{array}{l}4^{\text {th }} \\
\text { iteration }\end{array}$ & \\
\hline $\begin{array}{c}\text { S\&A manned } \\
\text { flight } \\
\text { campaigns }\end{array}$ & $\begin{array}{c}1^{\text {st }} \\
\text { iteration }\end{array}$ & & $\begin{array}{c}2^{\text {nd }} \\
\text { iteration }\end{array}$ & $\begin{array}{c}3^{\text {rd }} \\
\text { iteration }\end{array}$ & & \\
\hline $\begin{array}{c}\text { S\&A } \\
\text { unmanned } \\
\text { flight } \\
\text { campaigns }\end{array}$ & & & & $\begin{array}{c}1^{\text {st }} \\
\text { iteration }\end{array}$ & $\begin{array}{c}2^{\text {nd }} \\
\text { iteration }\end{array}$ & \\
\hline $\begin{array}{l}\text { Standardization } \\
\text { workshops }\end{array}$ & $\begin{array}{l}1^{\text {st }} \text { Standard } \\
\text { workshop }\end{array}$ & $\begin{array}{c}2^{\text {nd }} \\
\text { Standard } \\
\text { workshop }\end{array}$ & $\begin{array}{l}3^{\text {rd }} \text { Standard } \\
\text { workshop }\end{array}$ & $\begin{array}{c}4^{\text {th }} \\
\text { Standard } \\
\text { workshop }\end{array}$ & $\begin{array}{c}5^{\text {th }} \\
\text { Standard } \\
\text { workshop }\end{array}$ & $\begin{array}{c}6^{\text {th }} \\
\text { Standard } \\
\text { workshop }\end{array}$ \\
\hline
\end{tabular}

Figure 1: Iterative development of MIDCAS according to the project stages

\section{Initial stage: conceptual development}

The initial coordination of MIDCAS was based on the Statement of Work (SoW) and the division of the work packages (WPs) that was agreed on during the negotiation phase based on intensive face-to-face interactions prior to the project. After more than 40 preparatory meetings, the industrial partners felt sufficiently familiar with each other and comfortable with their assigned tasks and the agreed management model.

The complexity of MIDCAS was not only due to the content of the technical work, but also due to the distributed work of multiple partners. Most of the large companies in MIDCAS had experience with this type of projects before and were aware of the challenge. In the beginning of such project, you make an ideal assumption, and this ideal assumption in the reality needs to be adjusted to prove feasibility. In a context of many partners, you have a fully new project with a lot of uncertainties, which starts with people don't knowing each other, from different nations and with cultural differences.

This additional complexity added uncertainty to technical choices that had to be implemented in later stages of the project, making impossible to foresee at this stage. Therefore, to deal with this complexity, the project was planned to progressively achieve the main tasks with iterations rather than accomplishing its goals in one single task. One of the partners explained:

"It's quite clear that you cannot achieve the whole thing in one goal, and that is why we opted for iterations in the first place actually just to split up the whole work in smaller pieces."

At the end of each iteration, a set of documents and specifications would be available in a shared repository data for partners and stakeholders. At this stage, the understanding of the work to be integrated built on e-mail conversations, teleconferences and Skype meetings between geographically dispersed partners. Virtual communication at this phase was, therefore, sufficient. Face-to-face meetings like 
Workshops, took place mainly between key managers and other stakeholders. The work was coordinated mainly through virtual means until an acceptable set of requirements was agreed upon.

The management coordination stage was finalized by freezing an adequate set of requirements and specifications. At the same time, there was a growing awareness among the partners of the complexity of the system architecture, interdependencies, and possible problem areas. Therefore, by the end of this stage, when the main tasks were defined, tasks and roles were defined on a high level of design, and the partners were able to achieve a strong common understanding.

\section{Design stage: simulation, implementation and testing in manned and unmanned demonstrator}

The second stage started the R\&D activities of implementation, where participants would test their proposed solutions. To execute the tasks designed in the previous stage, the face-to-face meetings increased, as only virtual means of communication were not enough to provide a shared perspective of how to jointly execute the tasks. Therefore, a new coordination pattern, with more personal interaction, started to unfold.

An intense involvement of technical personnel is observed in this stage. With many participants with different backgrounds, cultures and experiences, coordination challenges were becoming more evident with difficulties to align expectations about tasks and roles. For instance, one of the WPs had 9 partners, which made consensus more difficult to achieve.

Some partners explained that the reason for some working groups had so many participants was a desire to maximize the benefits of participation and capture as much as information as possible. Because some working groups had too many partners, coordination of the tasks became a challenge to achieve consensus about how to execute the planned tasks and also emergent tasks.

At this stage, new tasks and task assignments were emerging as sub-products of the tasks completed before. When the scope of the emergent tasks was inside the scope of its parent task, then the correspondent roles assigned for the emergent tasks remained practically the same as for the parent tasks. The project management team had the right systems engineering tools to coordinate the execution of these new tasks and assign them to the appropriate partners. Those tools were based on risk management techniques and preplanned contingencies that are designed to deal with unfolding events.

On the other hand, when some tasks shown a high interdependency with other tasks, their emergent subtasks inherited a high degree of interdependency, resulting in a higher complexity to coordinate them. The use of preplanned contingency tools was not sufficient to manage the emergent tasks, and the management team had to learn about new dependencies and re-plan an appropriate response. Therefore, it was a challenge sometimes, for the coordinators to assign emergent tasks to the correspondent partners.

With some partners resisting to accept new assignments in some occasions, the project started to have some delays. To deal with this situation, a modification was made on the decision-making system, that was previously based on full consensus. Therefore, an additional rule gave the project coordinator the right to impose consensus when needed, even though each actor also had the right to escalate to a higher 
management level. However, after the activation of this supplementary rule, most conflicts could be solved without escalation to the higher level.

Also, in this stage, to improve familiarity, trust and shared understanding about the technical work, they implemented more face-to-face meetings, which they called extended workshops. The extended workshops were set up around critical areas within the working packages (WP). The objectives of these workshops were to implement the objectives of each iteration, gathering mainly engineers for problem-solving activities. These workshops were reported as very efficient for their slightly different concept from other types of meetings, as noted by the project manager:

“...the extended workshops were not meetings where you just sit around a table and someone presents something on a powerpoint, but really having the engineers sitting there and working together doing actual work and being able to talk to each other, throwing questions..."

Rather than setting a specific time frame for each workshop, the arrangement relied on an agreement that the workshop would not be finalized until a solution and forward plan was agreed upon. The workshops typically lasted for a period of about two weeks, after which the engineers returned home and continued to work on their agreed assignments for about six weeks. During this period, they frequently interacted through emails, Skype and telecoms to follow up the discussions before and plan the next topics to the next workshops.

This set-up was reported as a good compromise between face-to-face meetings and virtual communication, as it allowed partners to gain benefits from both modes. A key feature for this set-up was the timing between these modes. According to the project coordinator:

"If it's too long between the extended workshops, then things start to diverge. Even if you try to communicate as best you can, they still start to diverge, to have some frictions and misunderstandings, but if you have them at good intervals then you can sort of prevent that divergence."

Each partner also integrated and embedded the result of the extended workshops back into their own organizations through internal project meetings. As the extended workshops were a relatively costly mechanism, limited use was made of them. As they helped partners to increase their common understanding about tasks and the roles associated with the tasks, the use of extended workshops gradually decreased, shifting a major part of the communication process to virtual means.

\section{Concluding stage: simulation, implementation and testing in unmanned demonstrator and finalization}

Following the unmanned flight test campaigns, in the third stage, the more experienced partners increased their understanding of the broader context and improved common understanding of the critical parts of the project, not only among the industry members, but also among the stakeholders. Improved documentation provided a more fine-grained and detailed understanding and had an important role in the coordination of the project as impersonal mechanisms. For example, a better definition of the roles and task assignments avoided unnecessary participation from some partners in some work packages of the unmanned flight tasks, that would not add specific knowledge to 
them. Therefore, the partners learned better to balance their participation, moderating their roles and tasks against benefits.

The higher degree of common understanding at this stage facilitated coordination through virtual media and lowered the number of face-to-face meetings. Workshops at this stage were happening mostly during the scheduled activities for testing and evaluation on the unmanned flight campaigns.

The iterative process progressively produced and validated a consistent set of requirements for the generic solution for the Sense and Avoid system. The result of these efforts provided a great step forward to detail the solutions, and each test resulted in a considerable increase in the available codified documentation in the project in terms of released documents and specifications. This iterative approach helped to minimize risks and deal with unpredictable properties in a progressive way. Therefore, at this stage, the partners perceived a strong common understanding helped by the iterative approach, as the Chief Engineering said:

"In MIDCAS we learned how to do system engineering in an international environment. Because no one actually have done the bridging between the highest level of requirements down to the lowest level of integration and verification. So the first time you do this kind of bridging you see some issues with: either your integrated concepts or functions that you have designed or your operational scope that you can probably never fulfil. So you need to solve this iteratively, especially in a project with a lot of performance requirements."

\section{The iterative process}

The iterative process used in the project was considered very important to increase common understanding of the technical work. For example, the introduction of manned flight campaigns before the unmanned ones was considered a critical step to satisfactorily achieve the final goal. Even though some partners did not want to have the manned campaigns, due to increased costs and time, some partners thought that this intermediate step was essential to uncover some technical dependencies and to prove the competence of some companies.

This divergence of opinions was evidenced by one of the partners:

"At the aircraft integrator level you know that you can't wait until every input is defined and carved in stone. We know that it is a changing environment and you have to start with some assumptions, and as they change, you adapt. Whereas other firms won't start to work until everything is frozen, because they know that if they start to work and something changes, they will have to redo, resulting in more cost for them."

At each iteration, design modifications are made and new functionalities are added. The manned flight main task was supposed to deliver a full set of functionalities tested before the unmanned flight task and was divided in different subtasks (iterations):

- The first subtask, the sensor flight test campaign, consisted of recording data from available off-the-shelf sensors (Eletro-Optic, Infra-Red and Radar sensors), during flight tests and grounded tests in order to feed the initial steps of the function. 
- The second subtask tested the whole manned demonstrator system, including sensors and processing equipment with the initial basic S\&A functionality implemented.

- The final subtask added functionality and updates based on results from the previous campaigns to expand the testing to more challenging scenarios, like adding intruders into the airspace in a collision course.

The progressive implementation and testing of critical components and functionalities in subtasks allowed the partners to mature the generic function design for the next subtask. For instance, in one of the subtasks, one of the partners had the role to integrate a set of components and subsystems. This partner however, was used to do this kind of work with off-the-shelf hardware. When it came to integrate new developing hardware, this partner was not able to do it properly. Thus, this subtask became a new task with new dependencies and new partner's assignments. If this intermediate subtask was not planned before, this problem could be detected much later in the project, costing more time and money to solve.

This step-by-step process therefore, helped partners to understand each other's skills and competences. The communication of these results through stakeholder's reports, informal discussions in workshops and electronic media, allowed them to adjust the functionalities scheduled to be tested in the next main task, the unmanned flight campaigns.

By the end of each iteration, specifications and reports were refined informing partners and stakeholders about the progress. The short-term goals of the iterations helped the working groups to match their specific skills to the specific tasks. Moreover, partners could learn about the competences of other partners. The partners thus, had a progressively and increasing understanding not only about their own roles and tasks, but also about the roles and tasks of their partners.

\section{Discussion and Conclusion}

Relying on previous insights into coordination, multi-party alliances and Complex Product Systems, this study aimed to shed light on how common understanding interacts with coordination mechanisms, and how they evolve together to facilitate improved coordination in CoPS multi-party projects. The findings points the answer at managing tasks and roles as the project unfolds by: adapting different combinations of coordination mechanisms according to different stages of the project; and implementing an iterative process where tasks and roles evolve and mature progressively and problems are identified earlier, leading to a validated and consistent result.

\section{Theoretical Implications}

Previous studies have argued that impersonal mechanisms are more likely to be implemented at the early phases of a collaboration when complexity is perceived to be low, while personal mechanisms are more prevalent when problems arise ((Faems, Janssens \& Van Looy, 2010). However, this study points at a more complex dynamic.

The findings show an evolution in the use of coordination mechanisms by using personal, impersonal and virtual mechanisms and extend previous insights into creating common understanding in multi-party alliances through: 
- Refining tasks and tasks solutions through continuous improvement of impersonal coordination of the codified knowledge base;

- Converging the different perspectives of roles and tasks by adapting personal and virtual coordination mechanisms as the project unfolds;

- Using virtual coordination as a baseline to complement and reinforce the other mechanisms.

This study provides three main contributions to the literature of coordination in multi-party alliances:

First, the literature of coordination acknowledges that mechanisms like plans, rules, routines and familiarity create common understanding at the level of the whole interdependent task or work process (Cannon-Bowers \& Salas, 2001; Okhuysen \& Bechky, 2009; Pinto, Pinto \& Prescott, 1993; Reagans, Argote \& Brooks, 2005). This study not only explains the use of those mechanisms, but also suggests that coordination mechanisms vary depending on the circumstances. The balance of the use of coordination mechanisms, effect and are affected by an evolving shared perspective of emerging tasks and roles, which builds common understanding. Moreover, impersonal, personal and virtual coordination mechanisms are put in place to reinforce each other in a feedback loop that improves the definition of tasks and roles iterativelly, increasing consensus between partners and enhancing the coordination of the whole work.

Second, this research builds on Okhuysen \& Bechky, (2009) who relate common understanding with a shared perspective of tasks and roles. Okhuysen \& Bechky, (2009) acknowledge common understanding as a mean to accomplish coordination through using coordination mechanisms to integrate the interdependent task in a context of intra-organizational setting. My study extends their findings to an inter-organizational and complex setting where tasks and roles are not always clearly defined in the beginning. In a multi-party project, tasks and roles will evolve, and partners need to be prepared to learn new tasks dependencies and to deal with new tasks assignments. In this context, achieving common understanding about tasks and roles is much more critical. This study also highlights the importance of using coordination mechanisms in an iterative way. Coordination mechanisms can be very effective to coordinate incremental tasks. In this context, the mechanisms are used to solve parts of the whole and not the whole. Therefore, they need to be carefully used, balancing their costs against efficiency.

Third, previously it has been argued that objects contribute to the development and refinement of shared understandings of how the work itself is performed (Bechky, 2003; Okhuysen \& Bechky, 2009). Also, demonstrators are considered crucial to promote common understanding in a context of complex projects (Steen, Buijs \& Williams, 2013). My study complements this view by suggesting that demonstrators might help to create common understanding if they are managed iteratively. The progressive implementation and testing of critical components and functionalities in each flight campaign with the manned demonstrator, assisted the partners to identify, earlier, design problems. The iterative approach therefore had a crucial role in creating consensus between partners, especially in the design stage.

I suggest therefore that the iterative process is critical to minimize uncertainty and facilitate the work of managers who have to make strategic decisions to coordinate the project. This finding has a direct implication to the literature of multi-party alliances and CoPS where complexity and uncertainty makes strategic decisions in the long term difficult for managers, increasing the chances of failure in the alliance (Davies et al., 2011; García-Canal, Valdés \& Ariño, 2003; Hobday, 1998). 


\section{Practical Implications}

As a practical implication for managers of multi-party alliances this case provides some insights.

First, managers need to know that emergent tasks arise in multi-party projects, and that risk management techniques and preplanned contingencies might not be sufficient to deal with unpredicted events. As the project unfolds, the management team needs to learn about new task's dependencies and re-plan an appropriate response to the consequences that these emergent tasks will infer. One of these consequences is the creation of new assignments not planned before. Therefore, a high level of common understanding is needed to achieve consensus of the work to be done and who must do it.

Second, common understanding is not easy to achieve in a complex setting, and managers need to find suitable combinations of coordination mechanisms according to different stages of the project. These combinations are planned prior to the project, but the management team need to be flexible enough to adapt when needed.

The use of personal coordination mechanisms might be more required during the initial and design stages to jointly: negotiate and adjust contractual terms; propose design specifications; and engage in problem solving activities. This study suggests that common understanding in these first two stages is strongly supported by personal coordination mechanisms, especially with the use of extended workshops, where there is a balance with the use of virtual mechanisms in between. In the concluding stage, when familiarity and common understanding is supposed to be higher, personal mechanisms can be used mainly in the pre-scheduled workshops, seldom requiring extended workshops.

It is also suggested that initially, impersonal mechanisms establish a joint and agreed understanding of the project, decreasing the perceived complexity and necessity for personal coordination while controlling the costs of the project. When the design stage starts, the documentation of the project might not be enough to provide a finegrained understanding of the emerging tasks to be executed and roles assigned to them. Therefore, the use of personal mechanisms can temporarily replace impersonal mechanisms through face-to-face interactions. Nevertheless, if an increase in common understanding follows, impersonal coordination can gradually develop in parallel, as the specification matured, and management models are clarified. In turn, this improvement of impersonal coordination can follow an improvement of the body of codified knowledge, which helps to create common understanding.

The use of virtual coordination arguably provides a baseline for coordination through geographically dispersed projects, and communication through virtual means can helps all stages of coordination to initiate and follow up discussions, complement and reinforce other mechanisms and increase common understanding. In turn, an increase in common understanding, indicates that the use of communication through emails, Skype meetings and telecoms might also improve.

Third, to not be overwhelmed by complexity, the iterative approach can provides a solution to coordinate under uncertainty and interdependence. In a R\&D project, to accurately define all requirements and specifications in advance, is not always possible. However, in a multi-party project, not all partners might now that. Therefore, this study suggests that coordinators need to divide the work in iterations, trying to find a good balance between their efficiency and costs. The short-term goals of each iteration can help partners to see, from a closer range, viable solutions for each 
task. At each iteration, the partners can identify problems earlier, and progressively increase their common understanding of the functionalities needed for integrating the whole system.

\section{Limitations and Further Research}

This single case description and analysis provide comprehensive and detailed insights into a complex phenomenon that is difficult to capture by outsiders. The analytical generalizations made can be extended to complex collaborative innovation efforts, typically those that are performed in CoPS environments. However, the results should be generalized with some caution.

First, this is a multi-party project where the main coordinator is a governmental agency, the European Defense Agency (EDA). Therefore, the selection of the partners was not in full control of the industrial coordinators. In this situation, we have a unique case of heterogeneous firms with different backgrounds, experiences and working cultures trying to achieve common understanding. Many multi-party alliances are assembled by industrial coordinators having full power for selecting their partners, making the partnership more homogeneous. However, this same characteristic that makes difficult to generalize to all multi-party alliances, makes the dynamic of achieving common understanding more observable, reinforcing the findings.

Second, this is a R\&D project where the tasks are very interdependent. Many critical tasks need the results of other critical tasks to advance, and vice-versa, and they need to be executed in parallel. There are many R\&D projects where most critical tasks are sequential, and the degree of interdependency is lower. Again, this same characteristic that makes more difficult to generalize, highlights the complexity of coordinating interdependent tasks and roles, strengthening the conclusions about the interaction between coordination and common understanding.

Finally, this is a project where the industrial partners represent only one facet of the enterprise. Other important facets are represented by governmental bodies like EDA, that were coordinating the work in a higher level; the supervisors of each country (the MODs); and the regulatory bodies, like EUROCAE. All these stakeholders had a relevant input in many decisions made by the coordinators and therefore, had a great deal of influence in the achievement of common understanding. Future studies could complement this research, by considering the perspectives of these other stakeholders and finding other relationships between common understanding and coordination. For instance, coordination mechanisms for knowledge integration (Grant, 1996) in a CoPS multi-party context is an issue not much explored in this literature. Further research could investigate the role of specific mechanisms like simulations and demonstrators in integrating knowledge, and its implications for coordination and common understanding.

\section{References}

Alavi, M., Leidner, D.E. (2001) Review: Knowledge Management and Knowledge Management Systems: Conceptual Foundations and Research Issues. MIS Quarterly, 25, 107-136.

Axelson, M., Richtnér, A. (2014) Reaping the Benefits: Mechanisms for Knowledge Transfer in Product Development Collaboration. International Journal of Innovation Management, 19, 1550018. 
Ballard, D.I. (2003) Communicating and Organizing in Time: A Meso-Level Model of Organizational Temporality. Management Communication Quarterly, 16, $380-415$.

Baraldi, E. (2009) User-Related Complexity Dimensions of Complex Products and Systems (Cops): A Case of Implementing an ERP System. International Journal of Innovation Management, 13, 19-45.

Barqawi, N., Mathiassen, L., Syed, K., Vastani, S.F. (2015) Balancing Coordination and Autonomy during Post-Acquisition within a High-Tech Firm. International Journal of Innovation Management, 20, 1650036.

Bechky, B.A. (2003) Sharing Meaning across Occupational Communities: The Transformation of Understanding on a Production Floor. Organization Science, 14, 312-30.

Bengtsson, M., Kock, S. (2000) "Coopetition" in Business Networks-to Cooperate and Compete Simultaneously. Industrial Marketing Management, 29, 411426.

Cannon-Bowers, J.A., Salas, E. (2001) Reflections on Shared Cognition. Journal of Organizational Behavior, 22, 195-202.

Carlile, P.R. (2002) A Pragmatic View of Knowledge and Boundaries: Boundary Objects in New Product Development. Organization Science, 13, 442-55.

Chamakiotis, P, R Whiting, G Symon, H Roby (2014). Exploring transitions and work-life balance in the digital era. In: Proc. 22nd European Conference on Information Systems (ECIS 2014).

Davies, A, T Brady, A Prencipe and M Hobday (2011). Innovation in complex products and systems: Implications for project-based organizing. In: ProjectBased Organizing and Strategic Management, G Cattani, S Ferriani, L Frederiksen and F Täube (eds.), Vol. 28, Advances in Strategic Management, pp. 3-26. Emerald Group Publishing Limited.

Davies, A., Mackenzie, I. (2014) Project Complexity and Systems Integration: Constructing the London 2012 Olympics and Paralympics Games. International Journal of Project Management, 32, 773-90.

Denzin, NK and YS Lincoln (Eds.) (2008). Strategies of Qualitative Inquiry. Vol. 2, pp. 86-109. Thousand Oaks, CA: SAGE.

Eslami, M.H., Lakemond, N. (2015) Internal Integration in Complex Collaborative Product Development Projects. International Journal of Innovation Management, 20, 1650008.

Faems, D., Janssens, M., Van Looy, B. (2010) Managing the Co-OperationCompetition Dilemma in R\&D Alliances: A Multiple Case Study in the Advanced Materials Industry. Creativity and Innovation Management, 19, 322.

Faraj, S., Xiao, Y. (2006) Coordination in Fast-Response Organizations. Management Science, 52, 1155-69.

Furst, S.A., Reeves, M., Rosen, B., Blackburn, R.S. (2004) Managing the Life Cycle of Virtual Teams. The Academy of Management Executive (1993-2005), 18, 620.

García-Canal, E. (1996) Contractual Form in Domestic and International Strategic Alliances. Organization Studies, 17, 773-94.

García-Canal, E., Valdés, A., Ariño, A. (2003) Effectiveness of Dyadic and MultiParty Joint Ventures. Organization Studies - ORGAN STUD, 24.

Grant, R.M. (1996) Toward a Knowledge-Based Theory of the Firm. Strategic Management Journal, 17, 109-122. 
Greenberg, C.C., Regenbogen, S.E., Studdert, D.M., Lipsitz, S.R., Rogers, S.O., Zinner, M.J., Gawande, A.A. (2007) Patterns of Communication Breakdowns Resulting in Injury to Surgical Patients. Journal of the American College of Surgeons, 204, 533-40.

Gulati, R, F Wohlgezogen and P Zhelyazkov (2012). The two facets of collaboration: cooperation and coordination in strategic alliances. Academy of Management Annals, 6, 531-583.

Hansen, K.L., Rush, H. (1998) Hotspots in Complex Product Systems: Emerging Issues in Innovation Management. Technovation, 18, 555-90.

Heath, C., Hindmarsh, J., Luff, P. (1999) Interaction in Isolation: The Dislocated World of the London Underground Train Driver. Sociology, 33, 555-75.

Hobday, M. (1998) Product Complexity, Innovation and Industrial Organisation. Research Policy, 26, 689-710.

Liu, J., Su, J. (2014) Market Orientation, Technology Orientation and Product Innovation Success: Insights from CoPS. International Journal of Innovation Management, 18, 1450020.

Luo, Y., Park, S.H. (2004) Multiparty Cooperation and Performance in International Equity Joint Ventures. Journal of International Business Studies, 35, 142-60.

Malone, T. (1994) The Interdisciplinary Study of Coordination. Computing Surveys, 26, 87-119.

Massey, A.P., Montoya-Weiss, M.M., Hung, Y.-T. (2003) Because Time Matters: Temporal Coordination in Global Virtual Project Teams. Journal of Management Information Systems, 19, 129-55.

Merriam, SB (1997). Qualitative Research and Case Study Applications in Education: Revised and Expanded from Case Study Research in Education, 2nd edition, Wiley.

Mintzberg, H. (1973) The Nature of Managerial Work. Harpercollins College Div, New York, NY.

Noble, H., Smith, J. (2014) Qualitative Data Analysis: A Practical Example. Evidence-Based Nursing, 17, 2-3.

Nonaka, I. (1994) A Dynamic Theory of Organizational Knowledge Creation. Organization Science, 5, 14-37.

Okhuysen, G.A., Bechky, B.A. (2009) 10 Coordination in Organizations: An Integrative Perspective. The Academy of Management Annals, 3, 463-502.

Parkhe, A. (1993) Partner Nationality and the Structure-Performance Relationship in Strategic Alliances. Organization Science, 4, 301-24.

Pinto, M.B., Pinto, J.K., Prescott, J.E. (1993) Antecedents and Consequences of Project Team Cross-Functional Cooperation. Management Science, 39, 128197.

Prencipe, A., Tell, F. (2001) Inter-Project Learning: Processes and Outcomes of Knowledge Codification in Project-Based Firms. Research Policy, 30, 13731394.

Reagans, R., Argote, L., Brooks, D. (2005) Individual Experience and Experience Working Together: Predicting Learning Rates from Knowing Who Knows What and Knowing How to Work Together. Management Science, 51, 86981 .

Riege, A.M. (2003) Validity and Reliability Tests in Case Study Research: A Literature Review with "Hands-on" Applications for Each Research Phase. Qualitative Market Research: An International Journal, 6, 75-86. 
Siggelkow, N. (2007) Persuasion With Case Studies. Academy of Management Journal, 50, 20-4.

Simpson, TW, J Jiao, Z Siddique and K Hölttä-Otto (2013). Advances in Product Family and Product Platform Design: Methods \& Applications, 1st edition, Springer Science \& Business Media.

Smith, R.P., Eppinger, S.D. (1997) A Predictive Model of Sequential Iteration in Engineering Design. Management Science, 43, 1104-20.

Stake, RE (1995). The Art of Case Study Research, 1st edition, SAGE.

Steen, M., Buijs, J., Williams, D. (2013) The Role of Scenarios and Demonstrators in Promoting Shared Understanding in Innovation Projects. International Journal of Innovation and Technology Management, 11, 1440001.

Suter, WN (2011). Introduction to Educational Research: A Critical Thinking Approach, 2nd edition, SAGE.

Thompson, JD (1967). Organizations in Action: Social Science Bases of Administrative Theory, 12th edition, Transaction Publishers.

Van De Ven, A.H., Delbecq, A.L., Koenig, R. (1976) Determinants of Coordination Modes within Organizations. American Sociological Review, 41, 322-338.

von Hippel, E. (1990) Task Partitioning: An Innovation Process Variable. Research Policy, 19, 407-18.

Zakaria, N., Amelinckx, A., Wilemon, D. (2004) Working Together Apart? Building a Knowledge-Sharing Culture for Global Virtual Teams. Creativity and Innovation Management, 13, 15-29. 
Appendix 1

\begin{tabular}{|c|c|c|c|c|}
\hline Doc & Title & Authorship & Type & Pages \\
\hline 1 & MIDCAS - EASA and Unmanned Aircraft Systems (UAS) & EASA & Public Document (PPT) & 15 \\
\hline 2 & MIDCAS - Stakeholder Workshop \# 1 & MIDCAS Team & Public Document (PDF) & 95 \\
\hline 3 & MIDCAS - Minutes of First stakeholder workshop & MIDCAS Team & Public Document (PDF) & 72 \\
\hline 4 & MIDCAS - Second stakeholder report on analyses results & MIDCAS Team & Public Document (PDF) & 18 \\
\hline 5 & MIDCAS - Minutes of Second Stakeholder Workshop & MIDCAS Team & Public Document (PDF) & 26 \\
\hline 6 & MIDCAS - ACAS Compatibility & MIDCAS Team & Public Document (PDF) & 17 \\
\hline 7 & MIDCAS - Third stakeholder report on analyses results & MIDCAS Team & Public Document (PDF) & 20 \\
\hline 8 & MIDCAS - Minutes of third stakeholder workshop & MIDCAS Team & Public Document (PDF) & 27 \\
\hline 9 & MIDCAS - Concept Of Operations & MIDCAS Team & Public Document (PDF) & 129 \\
\hline 10 & $\begin{array}{l}\text { MIDCAS - Working Paper - Collision Avoidance concept and Operational aspects considered in } \\
\text { MIDCAS }\end{array}$ & MIDCAS Team & Public Document (PDF) & 25 \\
\hline 11 & MIDCAS - Traffic Avoidance Concept & MIDCAS Team & Public Document (PDF) & 31 \\
\hline 12 & MIDCAS - ATC Simulations & MIDCAS Team & Public Document (PDF) & 50 \\
\hline 13 & MIDCAS - S\&A System Simulation & MIDCAS Team & Public Document (PDF) & 22 \\
\hline 14 & MIDCAS - Performance Vs Safety Requirements summary and reflections & MIDCAS Team & Public Document (PDF) & 6 \\
\hline 15 & MIDCAS - Performance Vs Safety Requirements & MIDCAS Team & Public Document (PDF) & 25 \\
\hline 16 & MIDCAS - Project update & MIDCAS Team & Public Document (PDF) & 8 \\
\hline 17 & MIDCAS - HMI Questions \& Discussions & MIDCAS Team & Public Document (PDF) & 17 \\
\hline 18 & MIDCAS - Manned Flight tests & MIDCAS Team & Public Document (PDF) & 24 \\
\hline 19 & MIDCAS - Stakeholder Requirement Synthesis & MIDCAS Team & Public Document (PDF) & 48 \\
\hline 20 & MIDCAS - Sixth stakeholder report on analyses results & MIDCAS Team & Public Document (PDF) & 24 \\
\hline 21 & MIDCAS - Minutes of sixth stakeholder workshop & MIDCAS Team & Public Document (PDF) & 12 \\
\hline 22 & MIDCAS - Performance and Safety Case Considerations & MIDCAS Team & Public Document (PDF) & 57 \\
\hline 23 & MIDCAS - System Requirements Specification (SSS) covering operation in airspace A-G & MIDCAS Team & Public Document (PDF) & 87 \\
\hline 24 & MIDCAS - High Level Sense \& Avoid Requirements & MIDCAS Team & Public Document (PDF) & 41 \\
\hline 25 & MIDCAS - MID-AIR COLLISION AVOIDANCE FOR RPAS - FINDINGS FROM MIDCAS & Saab (Aerospace Conference 2016) & Public Document (PDF) & 18 \\
\hline 26 & Integration of Unmanned Aircraft Systems into the National Airspace System & Federal Aviation Administration & Public Document (PDF) & 120 \\
\hline
\end{tabular}

